\title{
"Conmemorar el pasado es mirar hacia el futuro". Reflexiones para el aniversario de la Asociación Europea de Arqueólogos
}

\author{
Este mes de septiembre se cumplen 25 años desde que la EAA (European Association of Archaeologists) \\ celebró su reunión inaugural en Liubliana (Eslovenia). En cierto sentido es una asociación muy pegada a \\ España, desde que celebró su primera reunión un año después en Santiago de Compostela, en 1995. Por \\ alguna razón España se ha mantenido a través de los años como una de las nacionalidades con mayor \\ número de miembros. El presidente de la EAA comparte en revista $\mathrm{PH}$ para el público hispanohablante \\ qué significa este 25 aniversario.
}

Felipe Criado-Boado | presidente de la European Association of Archaeologists

URL de la contribución <http://www.iaph.es/revistaph/index.php/revistaph/article/view/4450>

Aquella reunión de Santiago de Compostela congregó a más de 500 personas. Lo que pasó allí, para sorpresa de los propios organizadores, fue un síntoma de lo que sería después la EAA. Hay muchas anécdotas de aquellos días, que marcaron el nacimiento de la asociación. Subrayo tres. La conferencia coincidió con una visita oficial a Santiago de Mario Soares, presidente de la República de Portugal, de viaje oficial por España. Oliendo la oportunidad, los arqueólogos portugueses presentes solicitaron el apoyo oficial de la naciente EAA para dirigirse al presidente Soares y plantearle, con el apoyo de los y las arqueólogas europeas una protesta formal contra la inundación de Foz de Coa por la construcción del embalse proyectado. Soares reaccionó con reflejos y recibió a una nutrida delegación de participantes en la reunión que, además de unir a la delegación portuguesa, reunía personas emblemáticas de la arqueología europea (empezando por K. Kristiansen, primer presidente de la EAA) y Henry Cleere, una de las voces más autorizadas de ICOMOS en aquellos momentos. Soares tomó cuenta del movimiento y el futuro de Foz de Coa cambió. También el de la EAA, que se dio cuenta de su capacidad de movilización y quedó desde aquel día formalmente comprometida con la protección y valorización del patrimonio arqueológico.

Este signo lo subrayó perfectamente el segundo movimiento que comento. El joven, en aquel momento, Servicio de Arqueoloxía de la Xunta de Galicia, aprovechó la reunión de la EAA para convocar a todos departa- mentos de arqueología y patrimonio de las comunidades autónomas españolas y tratar temas comunes. Aquello dio lugar a una dinámica que se mantuvo durante un tiempo y que permitió fortalecer la naciente gestión y protección del patrimonio arqueológico en España. A pesar de que somos un país que debería reconocer su naturaleza de facto federal, aquella iniciativa se perdió más tarde. Pero para la EAA supuso la conciencia y el modelo de que podía crear una relación positiva con las circunstancias regionales y coadyuvar a su expresión y consolidación.

El tercer hecho es, sin embargo, el mejor o, al menos, el más significativo. Ya iniciada la reunión, me informan (yo era entonces lo que con el tiempo llamamos ahora el main organizer, colaborando con el grupo de investigación que hay en el Incipit) que en la puerta del palacio de congresos donde estábamos había dos rusos que querían registrarse pero no tenían dinero para pagar la inscripción. Se trataba de dos rusos que habían atravesado Europa en coche, desde Moscú, conocedores de que había una primera reunión de arqueólogos europeos en el confín de Europa y deseando fortalecer lazos con lo que allí pasase para entender mejor cómo seguir adelante en la convulsa situación, en aquel momento, de la antigua URSS. Pronto nos dimos cuenta de que la proeza del viaje de venida la reforzó el hecho de que no tenían dinero para vivir ni para afrontar el viaje de regreso. Inmediatamente tuvieron la solidaridad de todos, lo que no les libró de dormir en el coche durante 


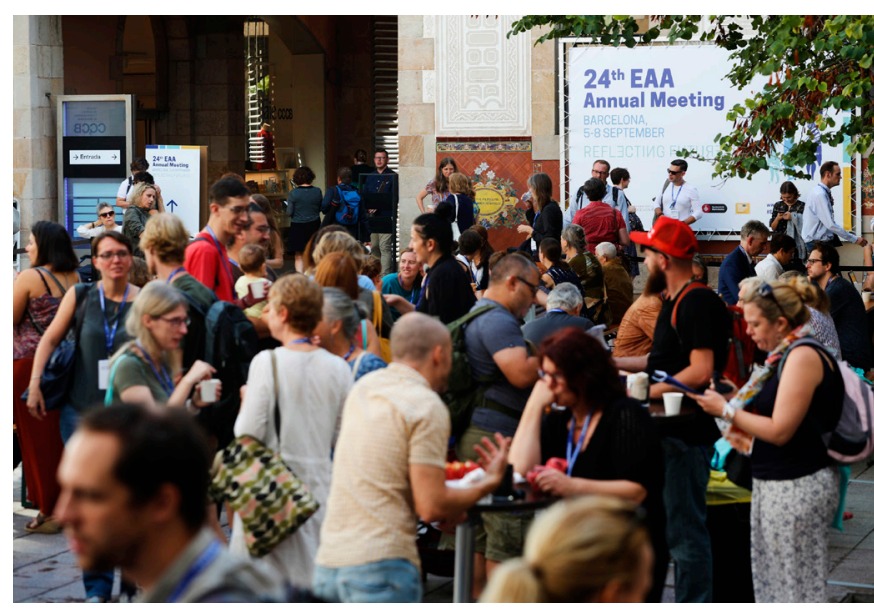

En las reuniones anuales de la EAA participa mucha gente joven y estudiantes foto todas las imágenes que ilustran esta contribución son de la EAA

los días del congreso. En aquel momento ya habíamos distribuido y agotado las ayudas que la Xunta de Galicia y, por primera vez, la Wenner-Gren Foundation había aportado financiar la participación de los miembros con menor capacidad económica, otra constante que se ha mantenido a lo largo de los 25 años de la EAA con singular esfuerzo siempre por intentar conseguir estos fondos que nunca son suficientes. El movimiento de aquellos rusos significó tres cosas muy claras: mostró la fuerza de la idea de una asociación paneuropea de arqueología, mostró que esa idea atravesaba claramente las fronteras de Europa Occidental, del antiguo Mercado Común y que tenía un sitio preferente en las expectativas de Europa del Este, y anticipó la firme apuesta que los países de Europa Oriental mantuvieron desde entonces con la EAA.

La asociación ha crecido mucho en este tiempo. En 1994 fuimos en Liubliana alrededor de 150 participantes. Este año en Berna (Suiza) nos juntaremos al menos 1.750, según las cifras de participantes registrados al escribir estas líneas (mayo de 2019). La reunión celebrada en Barcelona el año pasado reunió a más de 3.200 personas, y en ese momento la asociación alcanzó los 3.536 miembros.

Estas cifras sólo reflejan que la creación de la EAA, un proyecto que tomó forma entre 1992 y 1993, se adaptó perfectamente a las expectativas y necesidades de la

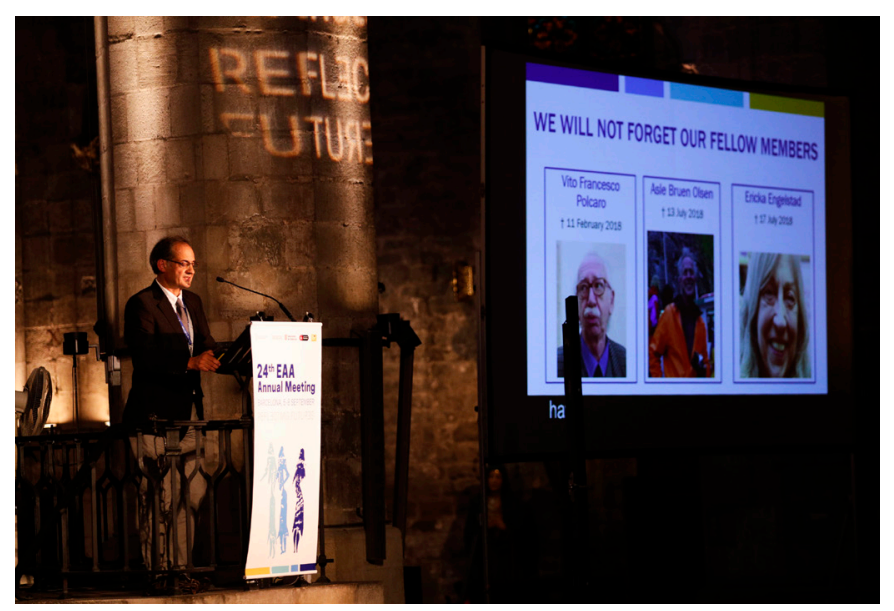

En las ceremonias inaugurales de todos los Annual Meeting de la EAA, se recuerda especialmente a los compañeros fallecidos el año anterior

arqueología europea y a la situación de nuestras sociedades y del propio proyecto europeo en aquel momento. La EAA fue concebida por sus fundadores (un nutrido grupo de arqueólogos y arqueólogas europeas a cuya cabeza estaban Kristian Kristiansen, Henry Cleere, y por parte de España Maribel Martínez Navarrete) como la forma para aportar a la arqueología europea una perspectiva transnacional, en términos tanto de práctica como de interpretación.

Desde entonces, 15.198 arqueólogos europeos y de todas partes han compartido la noción de que la arqueología y el patrimonio arqueológico necesitan pensar fuera de las fronteras y límites, sea para interpretar mejor el pasado, para fundar con mayor solidez nuestras prácticas, para consolidar redes o simplemente para hacernos más fuertes reconociendo la diversidad inherente a la arqueología europea. La creación de la EAA respondió a una intención muy clara de pensar la arqueología y los problemas arqueológicos por encima de los límites nacionales, con una perspectiva continental. Este impulso formaba parte de la expansión de un proyecto europeísta en el que se congregaban las naciones de Europa Occidental con las naciones posfascistas de la Europa mediterránea y las naciones postsoviéticas de Europa del Este. Baste recordar que en 1993 no había una sola revista que fomentara la publicación de estudios arqueológicos con una perspectiva transnacional, la adecuada para analizar fenómenos que ocurrieron mucho 


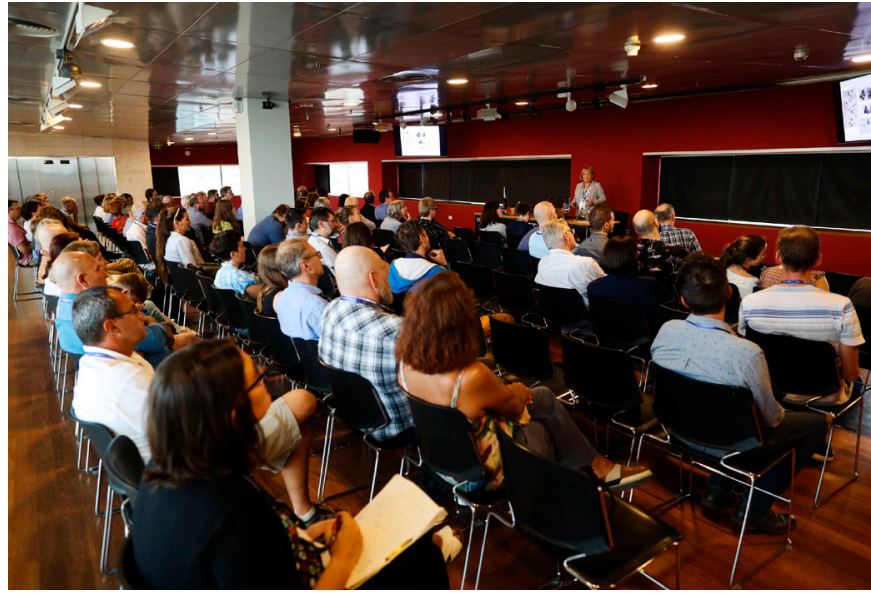

Sesión de la conferencia celebrada en Barcelona en 2018. En el ambiente de los Annual Meetings prevalece la discusión crítica y el diálogo

antes de que las fronteras de los actuales estados nacionales se hubieran asentado configurando la base territorial de la modernidad burguesa. Esa mera conciencia crítica abrió paso a la necesidad de proyectar lo que hoy es el Journal of European Archaeology (EJA, la revista de la EAA que ahora publica Cambridge University Press y ocupa la posición 27 en el ranking mundial de publicaciones periódicas de arqueología de Scimago. La creación del EJA (en 1993) alimentó la necesidad de crear la EAA; hacía falta una asociación para darle forma, sentido y una comunidad de lectores de referencia.

En términos historiográficos, de evolución teórica de la arqueología, la EAA surge en un momento en el que la emergencia disruptiva del postprocesualismo ya se había atemperado con la reflexión y la necesidad de asentarse en un mundo multipolar y diverso en el que irrumpían reclamando sus propios derechos otras tradiciones arqueológicas, nacionales, pero también indígenas y por supuesto las mujeres, a las que desde el primer momento se les reconoció un protagonismo necesario en la constitución de la EAA. Otra cosa es preguntarse hoy, 25 años después, si esto realmente ha permitido nivelar las relaciones de género y normalizar la perspectiva de género y femenina en la arqueología. Posiblemente habría sido peor si la EAA no hubiera hecho motivos en este sentido. Pero la situación actual nos recuerda que queda mucho por hacer y que no nos podemos dar por satisfechos.

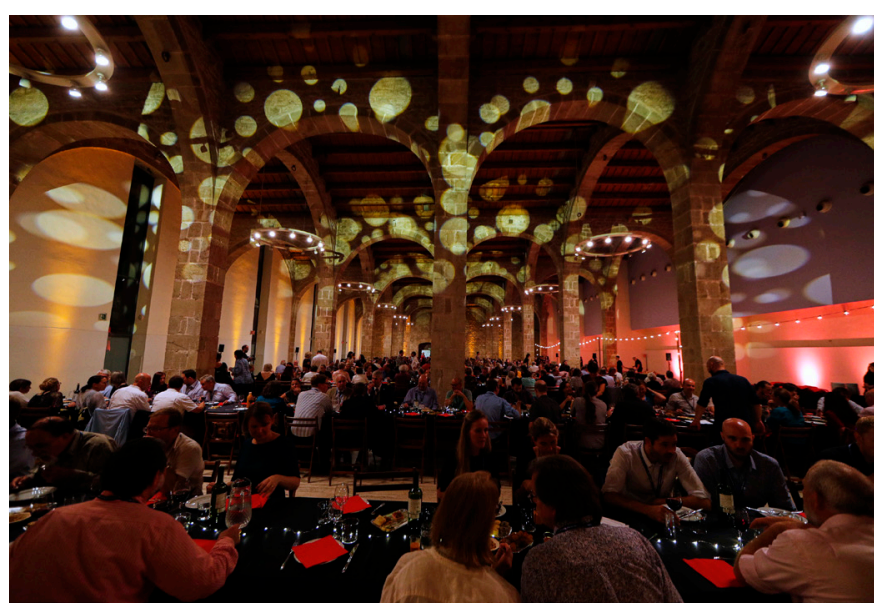

Cena de clausura del Annual Meeting de la EAA, Barcelona, septiembre de 2018

En aquel momento muchas cosas estaban pasando en la arqueología (la aprobación del Convenio de Malta de protección del patrimonio arqueológico en 1992, la emergencia de la arqueología comercial, el giro hacia el patrimonio arqueológico y la arqueología pública) y en la construcción de la unidad de Europa (el Tratado de Maastricht, también de 1992). La EAA se creó en un momento optimista, de crecimiento económico, aparente afianzamiento de la democracia, fortaleza de la idea de Europa y construcción del proyecto de Unión Europea. Todo el mundo puede comprobar cómo a su alrededor muchas iniciativas $u$ organizaciones cumplen 25 años; la misma revista $P H$ cumplió 25 años hace unos meses. Esta convergencia de celebraciones es un testimonio nítido de que aquellos eran tiempos positivos, llenos de actividad, y que la EAA pertenece a esa misma poderosa dinámica. Muchas cosas cambiaron en estos 25 años.

Es tan necesario como simplista decir ahora que, 25 años después, las cosas no son tan sencillas ni mantenemos el mismo optimismo. Hemos perdido la ingenuidad respecto a la Unión Europea que es sólo una versión posible, y claramente no la mejor, de la construcción de la Unidad de Europa. Pero además, el Brexit y los preocupantes movimientos paralelos que se dan de un modo u otro en casi todos los países europeos, a lado de la crítica populista a la democracia liberal, la ceguera del neoliberalismo, un capitalismo insaciable, un cambio climático fuera de control, el mundo multipolar, la 


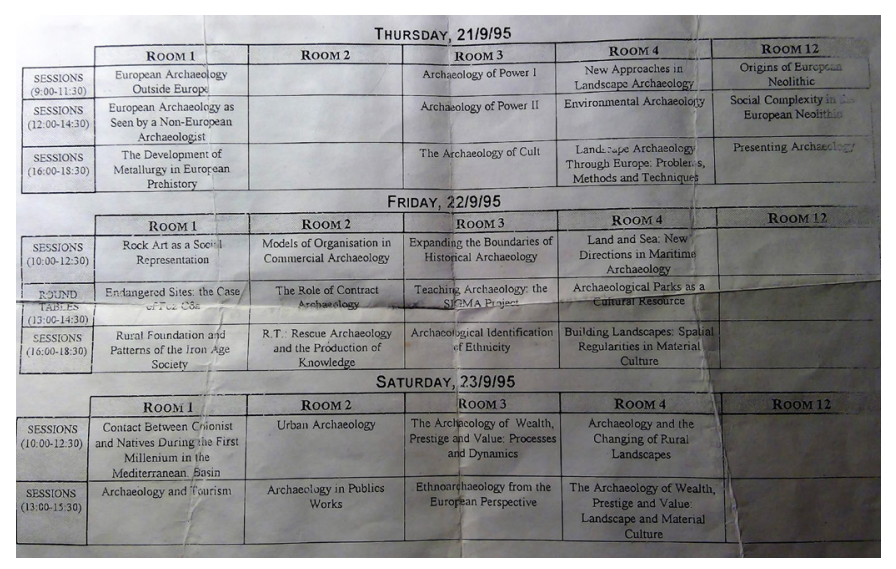

Programa académico de la primera conferencia anual de la EAA, celebrada en Santiago de Compostela en 1995, organizada por el grupo que después constituyó la base de lo que es hoy el Incipit (Instituto de Ciencias del Patrimonio del CSIC). Como se puede ver en el programa, desde el inicio las reuniones incluyen en pie de igualdad temas de investigación, gestión del patrimonio y política arqueológica y patrimonial: interpreting the Archaeological record, managing Archaeological Heritage, politics of Archaeological Practice

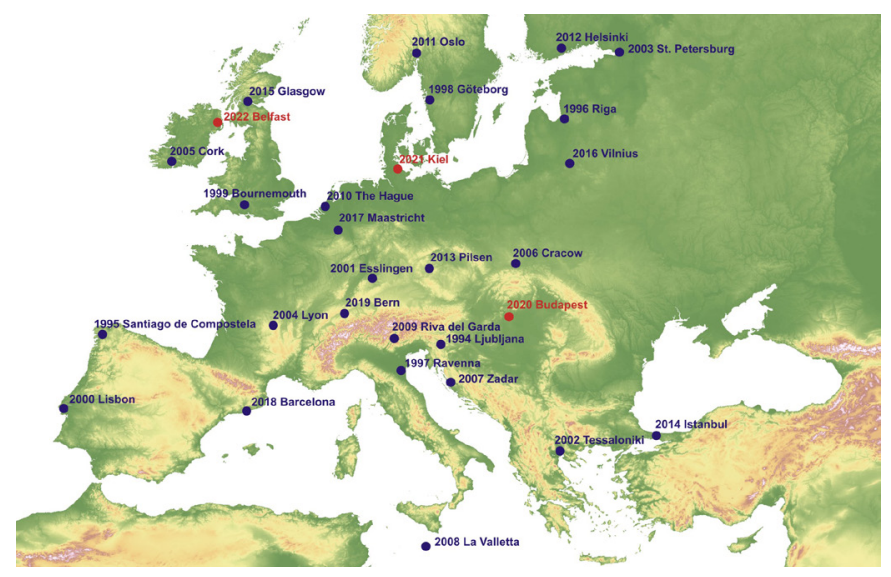

Durante 25 años, la EAA ha procurado llevar sus conferencias anuales a todos los rincones de Europa para favorecer el diálogo con las diferentes perspectivas y comunidades regionales que trabajan en la práctica y el patrimonio

arqueológicos. En el futuro seguirá manteniendo esta ambición. En el mapa se señalan las ubicaciones de los Annual Meetings de 2020, 2021 y 2022

descentralidad de Europa por primera vez en muchos siglos, el incremento de la movilidad poblacional de todo tipo (inmigrantes, refugiados, exiliados climáticos y por supuesto turistas), y la consolidación de la extrema derecha en casi todas partes, amenazan con disolver el proyecto Europeo y lo sustituyen por un neonacionalismo global y creciente. Es tan simplista decir como necesario ver que cada vez más gente se siente tentada por alternativas aislacionistas que privilegian perspectivas locales e intereses particulares.
Todo lo que parecía sólido en 1994, pareciera que se ha disuelto en el aire 25 años después y que con ello se desvanece la posibilidad de un proyecto progresista e inclusivo de Europa. Sin embargo tengo que hacer dos salvedades.

Mientras se creaba la EAA como parte de la oleada europeísta de inicios de los 90, la Europa balcánica se sumía en cruentas guerras que el resto de Europa no pudo, supo o quiso evitar. Cuando en el 94 estuve en Liubliana, me desaconsejaron ir a Zagreb. Visto ahora, 25 años después, creo que es preferible, en vez de entregarse a la nostalgia de considerar aquellos años como el pasado dorado del proyecto europeo, considerar esa coincidencia como el pecado original de la UE. No estoy seguro de que muchos burócratas en Bruselas o partidos políticos sistémicos lo vean del mismo modo.

Por otra parte, es cierto que tememos al nacionalismo excluyente pero yo, desde mi perspectiva, no veo nada de esto en la arqueología, entre los arqueólogos y particularmente dentro de la EAA. Sinceramente veo en la organización que tengo el honor de presidir, desde que fui elegido en Glasgow en 2015, un montón de energía positiva en personas que quieren que su trabajo, fundado en una perspectiva multilateral, en sólidas redes de interacción y en el diálogo entre actores reflexivos, contribuya al bienestar de nuestras sociedades, utilizando la arqueología para comprender el mundo y el patrimonio para reconstruirlo. No nos interesa tanto criticar todo lo anterior, particularmente el nuevo nacionalismo y el populismo reaccionario, sino entender desde nuestra perspectiva por qué esas posiciones cautivan a muchos conciudadanos. Y nuestra perspectiva es excepcional para entender esto, porque nos da acceso directo al análisis de la tradición, el patrimonio, la memoria y de los procesos que constituyen la identidad.

Desde 2017, los Annual Meetings ${ }^{1}$ de la EAA han adoptado un lema como referencia. La sucesión de ellos, cuidadosamente elegidos por cada organización local, los actores que convergen en ella y la Ejecutiva de la Asociación, perfilan el carácter actual de la EAA. En Maastricht en 2017 fue Building bridges, en Barcelona 
en 2018 Reflecting Futures, en Bern en 2019 Beyond Paradigms, en Budapest en 2020 Networking!!!...

No hay otra forma de conmemorar al pasado que mirando hacia el futuro, mirando para adelante. Cualquier otro modo conduce a una pulsión conmemorativa, celebratoria, que se resuelve en una cierta mezcla de nostalgia y autosatisfacción. La visión del tiempo lineal que nos han inculcado identifica el pasado con lo que está detrás y el futuro con lo que está delante. La arqueología ya no usa estas nociones simples de la temporalidad que derivan de la modernidad, sino que moviliza, cada vez más, representaciones complejas del tiempo social, a pesar de que muchos colegas insistan todavía en vincular la arqueología a la cronología y al pasado.

El futuro es hacia dónde vamos, y lo vemos delante. Pero el pasado es lo que nos permite ir hacia allí y también está delante de nosotros porque lo hemos visto; no lo olvidamos. Cuando miramos de frente, delante de nosotros se pliega el espacio-tiempo para superponer el pasado que fuimos y el futuro que queremos ser. De hecho, la ciencia cognitiva sabe que el sentido de la vista tiene al menos tanto que ver con la memoria como con los estímulos perceptuales que recibimos. Es más, lo que acabo de escribir bebe directamente en la concepción cultural del tiempo y el espacio en el mundo andino. Si tuviéramos esto claro, en vez de categorías metafísicas del tiempo lineal que hemos tomado por científicas y demostradas pero son sólo modernas, históricas y occidentales, tal vez entenderíamos mejor los problemas que hoy en día enfrentamos cuando las categorías heredadas de la Modernidad ya no llegan para explicar lo que nos pasa. No es que el pasado vuelva, es que estuvo siempre ahí.

La EAA celebra su 25 aniversario con ese ideario, porque esa mirada es la que nos permitirá sobreponernos a todas las limitaciones de nuestro pasado y que aún arrastramos en el presente. La EAA se dispone a celebrar sus primeros 25 años, en septiembre del 2019, haciendo una reflexión sobre cómo adaptar nuestra disciplina, nuestra profesión, para responder a los retos actuales. Para ganar el futuro toda comunidad debe articular la energía positiva que contiene, lo que también es cierto para

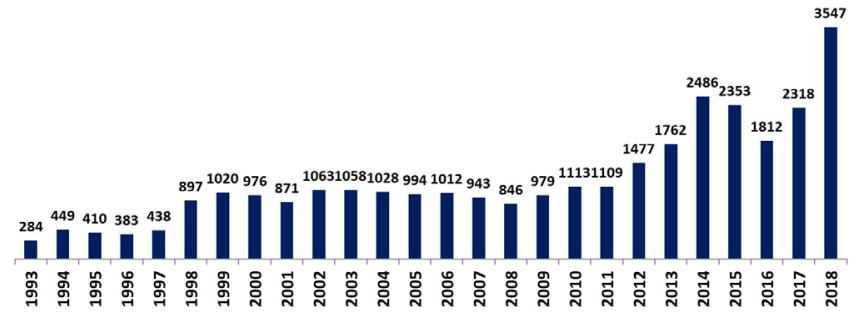

Evolución del número de miembros de la EAA a lo largo de sus 25 años de historia

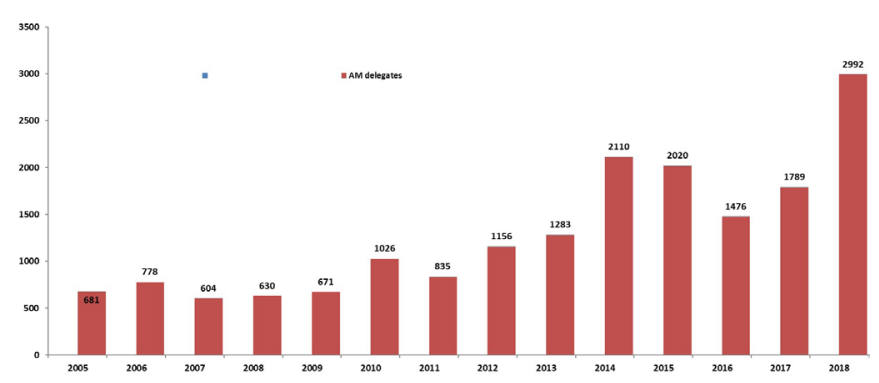

Evolución de la participación en los Annual Meetings de la EAA desde su fundación

la EAA y la investigación científica. Frente a las retóricas corrientes que, a través del énfasis monocorde en la innovación y el emprendimiento, sitúan esa ambición en las disciplinas científicas estándar, en la EAA somos conscientes de que las humanidades (y por lo tanto también la arqueología) deben reclamar y justificar su especial contribución a esta tarea. Esto es especialmente cierto para todas las disciplinas que trabajamos con el patrimonio.

Si algo hemos aprendido es que no llega con "investigar" y "trabajar" en espacios virginales. Este solipsismo es menos frecuente en la arqueología que en otras disciplinas (aunque personalmente tenga dudas de hasta qué punto esto es también cierto para la mayor parte de la arqueología académica) porque la fuerza de la arqueología pública, comunitaria, el activismo, el trabajo en las trincheras de la memoria histórica por parte de la arqueología del pasado contemporáneo, la etnoarqueología y muchas otras prácticas de este tipo, han impuesto este carácter a la arqueología desde hace años. Una asociación de profesionales tiene que reflexionar sobre las dimensiones socio-políticas del conocimiento y el patrimonio arqueológicos para posibilitar la alineación de las 


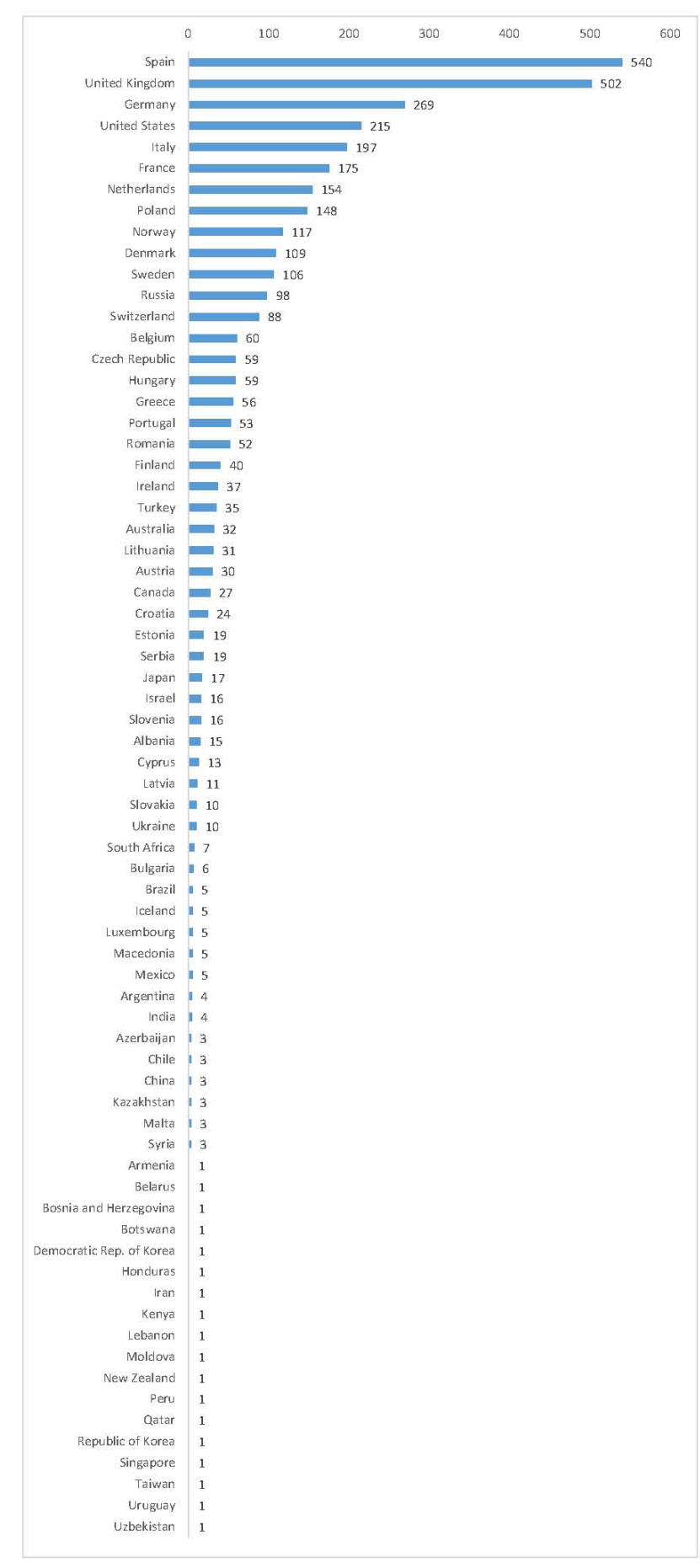

Descomposición por nacionalidades de la membresía de la EAA. La Asociación siempre acogió una representación global, con miembros de todos los países europeos y muchos otros prácticas corrientes con las nuevas necesidades. En este sentido la EAA, además de difundir esta visión y apoyar las acciones de nuestros miembros, ha puesto en marcha dos medidas concretas en estos meses que cito sólo como ejemplo de cómo se debe alinear el compromiso político del tipo de asociación que en inglés se denomina learned society.

En el congreso de la EAA del 2019, que se celebra en Berna (Suiza) en septiembre, la EAA discutirá la aprobación de una declaración especial, realizada con motivo de nuestro 25 aniversario, sobre la "Arqueología y el futuro de las sociedades democráticas". Si es aprobada, será publicada en su momento. Otro ejemplo es que, con motivo de las elecciones europeas de 26 de mayo de 2019, la EAA inició dos años antes un proceso para preparar unos benchmarks o términos de referencia sobre "arqueología y protección del patrimonio" que la EAA presentó a los grupos políticos que se presentaron a las elecciones con la finalidad de discutir con ellos cómo abordan esas temáticas y colocar esos problemas en la agenda política europea. Al margen de lo que ahí se dice, me parece importante resaltar que esta iniciativa ofrece un modelo concreto del tipo de actitud que los expertos y organizaciones profesionales deberíamos adoptar ante la política y nuestros políticos.

Demasiado a menudo vemos que éstos no parecen interesados en los temas que en cambio preocupan a la gente común. Más habitualmente nos quejamos como ciudadanos del divorcio entre política y realidad. La ciencia y los investigadores son un buen ejemplo, pues elección tras elección vemos a los y las científicas quejarse de que la ciencia no aparece casi en los programas y no ocupa tiempo en declaraciones, mítines o debates. La fisura entre práctica política y ciudadanía es un aspecto básico de la crisis de representación, que es una de los puntos críticos en la crisis epocal que vivimos.

El tema es complejo y no admite solución fácil. Pero creo que hay que entender que las prioridades y perspectivas de los grupos políticos no coincidan con los de la ciudadanía; se trata de puntos de vista distintos cuyas diferencias se pueden admitir mientras los partidos no nieguen las prioridades que se les plantean desde la otra 
perspectiva. Por eso mi impresión es que es tan normal que los políticos se olviden de hablar de ciencia, o de patrimonio o de arqueología, como conveniente es que desde iniciativas organizadas por la ciudadanía y comunidades expertas se les fuerce a hacerlo.

Esa es la idea de la EAA y por eso conjuramos la iniciativa benchmarks. Muchas otras organizaciones y grupos organizados de público deberían promover iniciativas similares. El Instituto de Ciencias del Patrimonio, al que pertenezco (dependiente del CSIC y con sede en Santiago de Compostela) promovió un debate con las candidaturas que concurrían a las últimas elecciones locales en la ciudad de Santiago sobre "patrimonio, turismo y ciudad". El resultado confirmó la oportunidad y viabilidad de este tipo de iniciativas. Más colectivos de expertos y profesionales deberían hacer lo mismo. El reenganche de los políticos con la ciudadanía no es una empresa unidireccional, sino una tarea que nos compromete en las dos direcciones. Es más, posiblemente seamos los expertos los principales responsables en favorecerla.

\section{NOTAS}

1. Estas reuniones, conferencias anuales, se celebran en los primeros días de septiembre. Ocupan tres días y medio más excursiones y actividades previas de los comités, comunidades y grupos de trabajo que integran la organización. Las reuniones se plantean a partir de un lema que funciona como expresión del ideario de la asociación para ese año y con base en una serie de temas generales en torno a los cuales se organizan sesiones temáticas. Las sesiones constituyen la unidad básica de la conferencia, no la comunicación o paper. Esto permite mantener año tras año un ambiente constante de diálogo y debate que constituye uno de los atractivos esenciales de la EAA y sus conferencias. Una vez pregunté a un grupo de arqueólogos y arqueólogas jóvenes por qué venían a las reuniones de la EAA y la respuesta fue unánime: "porque aquí nos dan feedback", el mismo que les falta en sus entornos de procedencia. La confección del programa pasa por dos procesos sucesivos de revisión por pares, primero las propuestas de sesiones y después de comunicaciones. 